\title{
Recent trends on applications of 3D printing technology on the design and manufacture of pharmaceutical oral formulation: a mini review
}

\author{
Nasim Samiei ${ }^{1,2}$
}

\begin{abstract}
Background: Three-dimensional printing (3DP) is an emerging technology used to describe 3D products manufactured on a digital design platform and in a layer by layer fashion. 3D printing technology has appeared as a major technological revolution of the recent years leading to the manufacturing and production of novel medical products and devices in pharmaceutical industry. The new technology has gained considerable attraction when the first commercial 3D tablet Spiratam ${ }^{\circledast}$ (levetiracetam) was approved by FDA in August 2015.

Main text: The key aspect of printing technology in the field of drug delivery is its versatility to create potential novel oral dosage forms. It also enables rapid, safe, and low-cost development in the production process which consequently leads to wide applications of this new technology in pharmaceutical fields. 3D printing also enhances patient convenience to further improve the medication compliance.

Among various technical trends for fabricating 3D objects, extrusion-based printing, powder-based binding, and inject printing methods are of particular interest to the pharmaceutical industry which are discussed briefly in this paper. This study also provides different applications of 3D printing technology and highlights the impact of 3D printing as an innovative promising technology through presenting some examples as experimental studies in the fabrication of oral drug delivery systems.

Conclusions: Through reviewing some experimental studies, this mini review has shown that 3D printing technique can be successfully used on a small scale to produce tailored doses of drug products and has great advantages experimentally in the production of oral doses forms. Concerning the future of 3D printing, the new technology is likely to focus on production in hospitals and pharmacies for individuals or niche groups with specific needs.

3D printing may also offer an attractive new research and development opportunity to improve drug formulation and administration of existing active pharmaceutical ingredients.
\end{abstract}

Keywords: 3D printing technology, 3D drug product, Customized medicine, Enabling technology, Customized release profile, Local fabrication

\footnotetext{
Correspondence: nasimsamieida@gmail.com

${ }^{1}$ FakherPharma Pharmaceutical, P.O. Box 14155-6153, Tehran, Iran

${ }^{2}$ Department of Pharmaceutics, Pharmaceutical Sciences Branch, Islamic Azad

University (IAUPS), Tehran, Iran
} 


\section{Background}

Three-dimensional printing (3DP) is an emerging technology used to describe 3D products manufactured on a digital design platform in a layer by layer fashion. 3D printing was originally developed with industrial application purposes and has progressively become a promising technology within past few years. Emergence of 3D printing in the pharmaceutical industry has led to radical shifts in the manufacturing process of drug products and has markedly enabled non-digitalized medical products to turn into digital 3D content [1-3]. On the other hand, there is a co-existence between physical and digital production which leads to manufacturing diverse models of 3D medical products. 3D printing technology has appeared as a major technological revolution of the recent years in pharmaceutical industry in terms of process innovation in the fabrication of $3 \mathrm{D}$ medical products [4-6]. The major shift toward development of $3 \mathrm{D}$ printing technology in the pharmaceutical industry was initiated in the early 90s at MIT (Massachuset Institute Technology, Cambridge, MA, USA) with a rapid prototyping method invented and patented by Sachs et al. entitled as "three-dimensional printing techniques." Despite the slow growth and adoption of the new technology, the first commercial 3D tablet Spiratam ${ }^{\bullet}$ (levetiracetam) was approved by the USA Food and Drug Administration (FDA) in August 2015 and was released to the market. The new 3D tablet enables epileptic patients to use a high dose tablet in emergency situations with no water and with a fast onset of action [7, 8].

Nowadays, pharmaceutical 3D printing is gaining considerable attention as a potential technology enhancing efficacy, preciseness, and individualisation while reducing wastage cost. The new technology also enables creation of novel oral dosage forms and medical devices which are otherwise challenging to be produced using conventional manufacturing technologies [9-11]. The ambitious goal of extensive research of $3 \mathrm{D}$ printing is to develop a technology which is capable of replacing all or most parts of conventional fabrication process of medical products. The technology is highly disruptive and can lead to remarkable innovation in different processes of drug development [12, 13].

The advent of 3D printing technology in the pharmaceutical industry has made it possible to design and manufacture novel complex drug products, as well as multiple active drug pharmaceutical ingredients (API) into one dosage form with customized release trends and individualized design adapted to patients' specific needs. These individualized dosage forms can be directly fabricated in a pharmacy on a local 3D printer or even at home by the patient. Indeed, the main advantage of the $3 \mathrm{D}$ printing is its flexibility to design and fabricate diverse medical products [14-18].
While a comprehensive review of the recent literature of this field is beyond the scope of this manuscript, this mini review aims to briefly review the $3 \mathrm{D}$ printing technology as an innovative enabling technology and its applications in pharmaceutical industry. The methods used in this study encompasses targeted literature searches focused upon emerge of three-dimensional printing (3DP) technology in the pharmaceutical industry and its contribution in the fabrication of novel oral drug delivery systems in main databases such as PubMed, Scopus, and Web of Science. Peer-reviewed published articles were chosen from established and well-regarded recent scientific journals.

The suitability of 3D printing was assessed as an enabling technology through investigation of printing different ranges of drug products from poorly water-soluble drugs and proteins. Different manufacturing processes such as extrusion-based printing, powder bed, and injection printing technologies which are widely used in fabrication of oral solid dosage forms, will also be discussed.

\section{Main text}

\subsection{Interplay between 3D printing and conventional manufacturing technique}

Solid oral dosage forms such as tablet and capsule are common routes of drug administration. Traditionally, they are produced by mass fabrication which involves multiples processes such as blending, mixing, milling, and finally compression into tablets. Furthermore, the conventional manufacturing techniques are intended to be a large-scale mass production with a one-dose-fit-all approach which may not necessarily consider the individual needs of a patient. The major disadvantages of the traditional manufacturing process include being time-consuming and costly while also requiring highly skilled technicians [19, 20].

The 3D printing technology seems to be a revolution in pharmaceutical manufacturing processes which is fundamentally different from the traditional mass production methods. With the introduction of $3 \mathrm{D}$ printing in the pharmaceutical industry, it is possible to curtail the process of manufacturing drug products from days to a matter of hours. Speeding up the production process can lead to more rapid release of the drug product into the market. In addition, the ability of $3 \mathrm{D}$ printing to rapidly manufacture a drug product causes a substantial cost reduction in the production process, which is highly favorable to the pharmaceutical industry. Further, it promotes creativity, innovation, and customization [21-23]. The fabrication steps with 3D printing are clean and the material waste is negligible allowing for previously discarded raw materials to be further explored, while also increasing compliance and accessibility of drugs. Nowadays, the number of research with $3 \mathrm{D}$ technique is 
growing which intends to leverage the arising profit of this technique in the pharmaceutical field [24].

In regard to manufacturing tailor-made medicine via traditional methods, general approaches involve utilization of high chain polymeric materials or waxy lipids to embed the drug substance for prolonging its release rate [25]. Development of such modified release products such as matrix embedment, core-coat, and multi-compartment systems may have few disadvantages such as accidental burst release of the drug from the dosage form which can lead to toxicity and adverse side effects. In this regard, 3D printing technique enables alternative manufacturing routes for advanced drug delivery systems with flexibility in the creation of oral dosage forms with a complex geometry. This can potentially address the issues related to the traditional modified release dosage forms and ultimately enables more effective way of personalized medications [26].

The ability of the technique in rapid production through a computer-aided design (CAD) allows for fast fabrication of a medicine with stability issues during the production process thus affording the opportunity of using the medication right after its immediate production $[9,14]$.
Hence, 3D medical products should meet the same quality and standard of conventional dosage forms with Good Manufacturing Practices (GMP) guidelines $[24,27]$.

Nevertheless, 3D printing technology is still an immature technique and has not yet been fully exploited due to its limitations. The fabrication of 3D products require different types of technologies in particular those used in pharmaceutical production, which are often rarely available in the pharma industry [20].

Some important advantages of 3D printing technology in oral drug delivery system are highlighted in Fig. 1.

\subsection{Manufacturing trends for fabrication of 3D printed medical products}

A 3D printing medical product can be generated by a set of different processes that replace the ink with a desirable formulation of drug and then jet that onto a suitable substrate in an additive process. The substrate may be an edible sheet with a functionalized structure of specific hydrophobicity/hydrophilicity, porosity, and permeability. The main challenge of $3 \mathrm{D}$ printing technique is

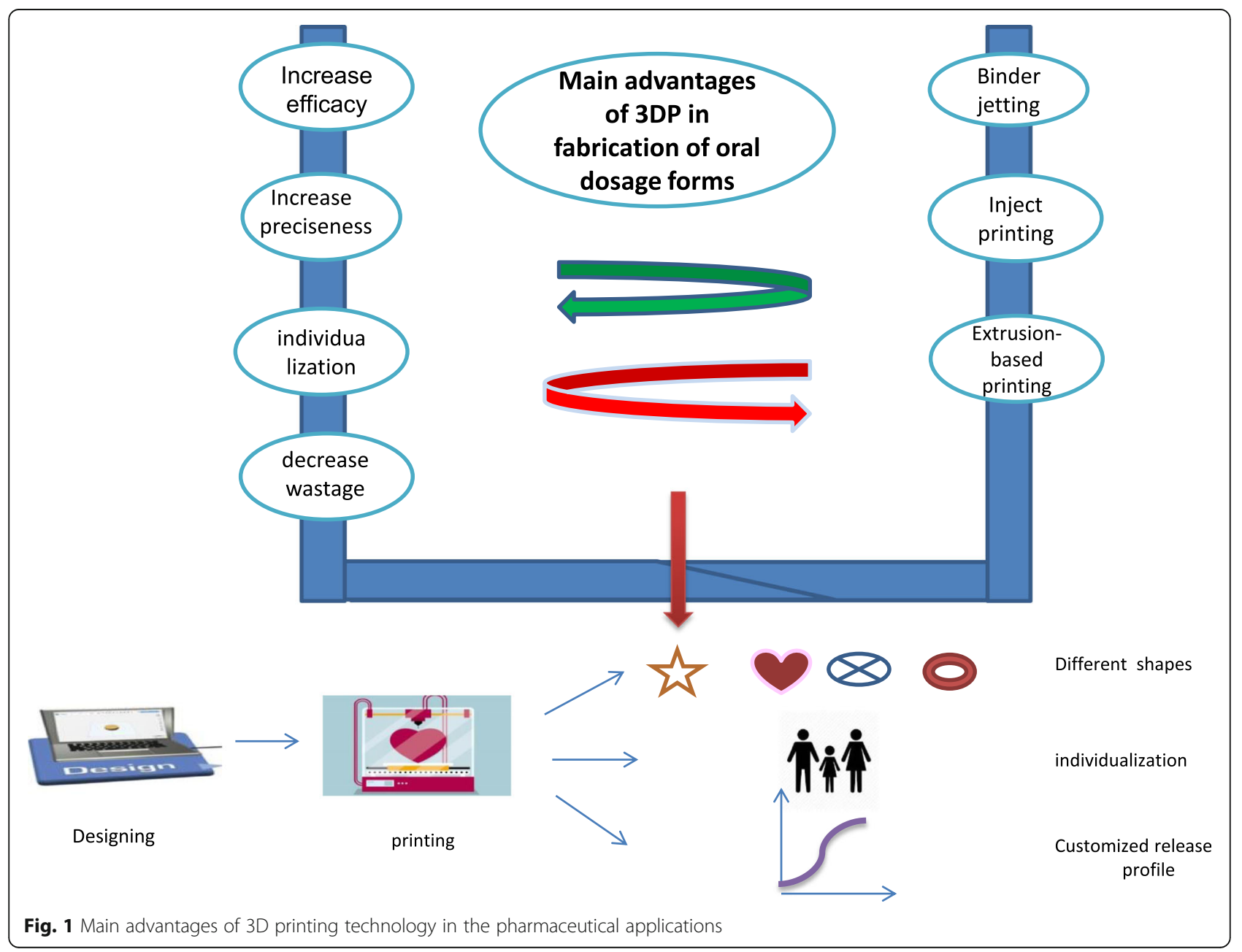


to convert the starting materials (drug and excipients) into a "curable ink" or a printable material $[19,28]$.

The first step of manufacturing a 3D object involves designing a digital model of the desired 3D product by a special CAD (the software comes in many forms and licenses). Next, the digital design is exported to a readable format for a system which is mainly a stereo lithography (STL) file. Afterwards, a slicer (3D printing software) transfers the STL file into a series of thin layers with the instruction tailored to generate the 3D object.

Then, during the course of printing, the printer head moves and the formulation ink decomposes onto successive layers on a built tray which will create the basis for the object. The process continues until the desired 3D product is constructed.

Finally, the 3D product may require movement of solvent residues, excess powder, polishing, and sintering which occur in the post-printing step $[11,19]$.

$3 \mathrm{D}$ printing has a potential to process versatile materials such as polymers, waxes, metals, and hydrogels. The technique is even used for the production of objects made from a single material or a combination of materials, where each material may be deposited by a separate print head or other deposition steps [5].

While 3D printing is widely used for the products which have been created layer by layer, other terms such as rapid prototyping, solid free form fabrication, and additive manufacturing have also emerged as other names and can be referred to as 3D printing. These terms have been introduced by manufacturing companies to reflect a special design for $3 \mathrm{D}$ products [8]. A summary of 3D printing process is represented in Fig. 2.

\subsection{D technology adoption in the pharmaceutics}

There are a number of technical trends for fabricating $3 \mathrm{D}$ printing products which can be used in the pharmaceutical industry and correspond to different applications and materials. These various methods vary in their function and productivity, where the key difference between them is the way a layer deposits on another layer. In addition, speed, accuracy, quality, and material properties are the major criteria which should be considered in selecting a suitable method for $3 \mathrm{D}$ printing $[5,29]$. The main characteristic of a 3D medical product such as drug load and its release rate can be precisely modified by printing parameters such as manipulating the numbers of printed layers for a given area or changing the entire area of printing [19].

Through reviewing some literature, a brief overview is presented about the most relevant 3D printing techniques adopted in the pharmaceutical industry such as extrusionbased technique, powder bed, and material jetting.

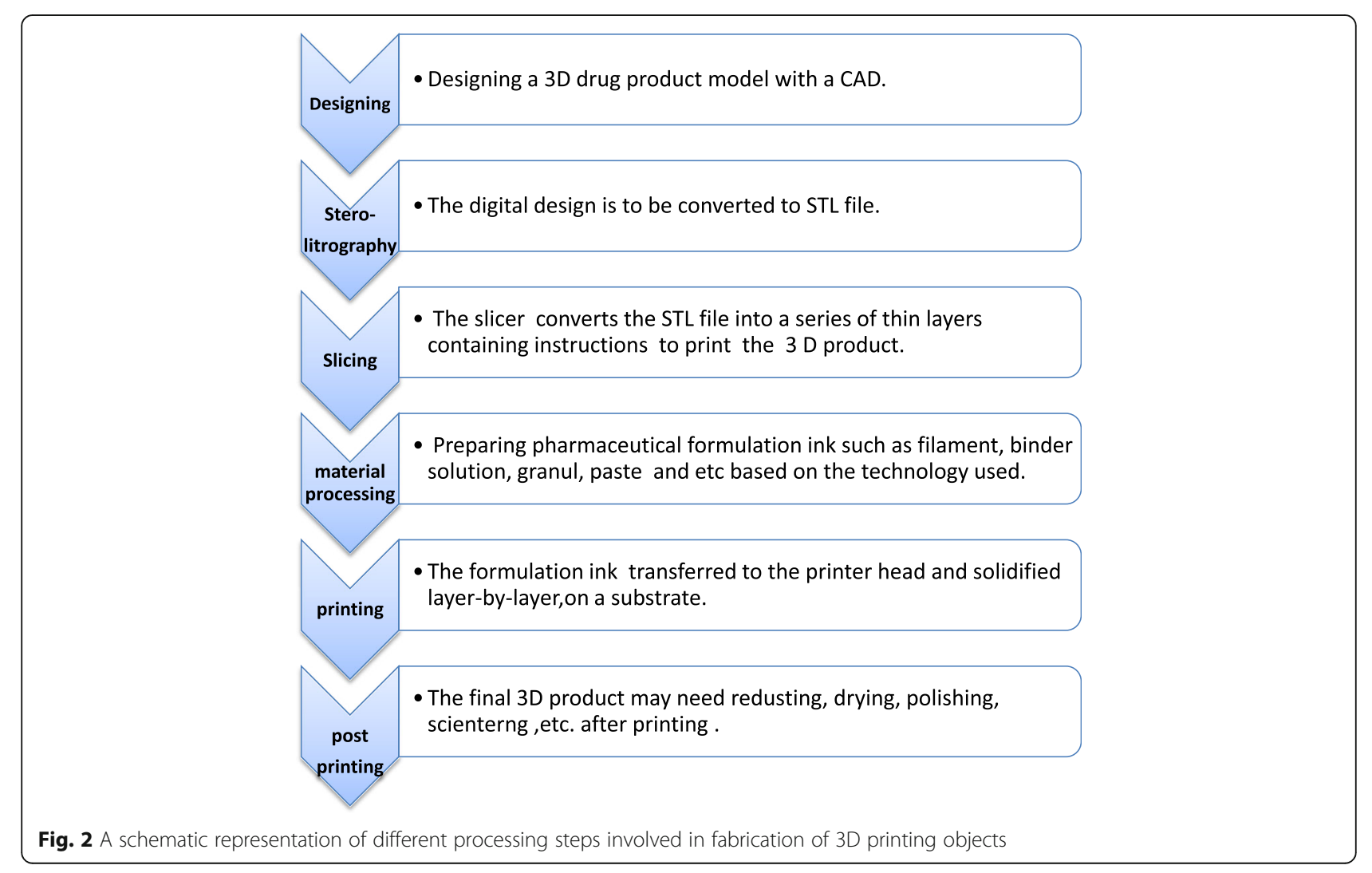




\subsubsection{Extrusion-based printing}

The trend of using extrusion printing technology started in 1980 and became operational in 1990. Extrusion printing technique is governed by two types of printing methods including hot melt extrusion (HME) technique and fused deposition modeling [30, 31].

In the case of HME technique, a homogenous solid dispersion of pharmaceutical excipients such as polymeric materials and plasticizers are prepared in a molten form of polymer and a drug substance is introduced in the polymeric composition. Next, the formulation ink can be extruded directly through a die under high pressure and elevated temperature, then fused and solidified after printing, thereby generating a $3 \mathrm{D}$ product of uniform shape with a high quality and drug content [32].

The advantage of hot melt extrusion is that it is a solvent-free method which eliminates the need for a rigorous solvent selection step, making it an environmentally friendly method of production $[11,25]$.

In the late 1990, with emergence of thermoplastic polymers such as polylactic acid (PLA), polyvinyl alcohol (PVA), and ethylvinyl acetate, 3D printing was introduced as a great adaptation in the pharmaceutical industry $[33,34]$.

Concerning the fused deposition method, the drug substance is loaded in a thermoplastic polymeric filament for example via passive diffusion from solutions and used as starting materials. Next, it is extruded by a gear system in a continuous profile through the heated printer head onto a surface and immediately hardens layer by layer upon leaving the printer. The fused deposition technique is also known as fussed filament (FF) in the literature. In comparison with the hot melt extrusion printing, in fused deposition modeling, the mechanical properties of 3D products and the drug load are lower. Further, the fused filament method can be efficiently used as a 3D printer for local or home-fabricated products for personalized medicine at the point of use $[35,36]$. Figure 3 displays a schematic illustration of the extrusion technique [37].

Both of the methods have gained popularity for fabricating 3D drug products in the pharmaceutical industry. The main advantage of the $3 \mathrm{D}$ extrusion printing technique is its high flexibility to develop a novel formulation of solid oral dosage forms with a different geometry, complexity and hallow structure product and various drug release profiles, and the ability to print a different range of polymers. Also, the extrusion technique is a promising way to printing materials in an amorphous form which enhances the dissolution rate thereby improving the bioavailability of poorly soluble drugs [27, 38-40].

\subsubsection{Powder-based binding method}

Rapid prototyping with a powder-based method is of particular interest to the pharmaceutical industry as it has many parallels with current manufacturing processes and may offer a more efficient longer-term printing solution [12]. Multilayers of 3D printing products are constructed by spraying a solution of binder or drug

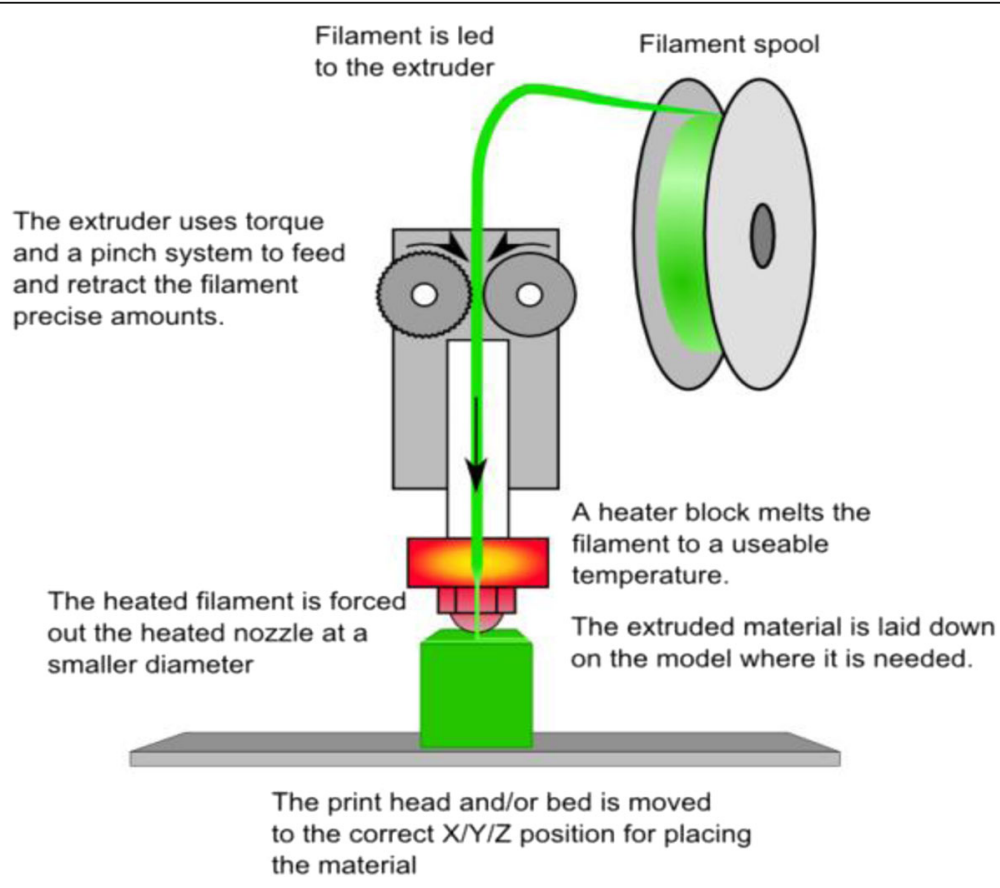

Fig. 3 Schematic representation of fused deposition modeling, reused from free copyright website RapRap (https://reprap.org/wiki/File:FFF.png) 
with additional excipients in small droplets from an $\mathrm{X}-\mathrm{Y}$ print head (in two-dimensional manners) over a powder bed on a built platform. Then, it is lowered along $Z$-axis based on the height of layers until the subsequent layer is constructed. The layers could be bonded via adhesion or welding in a liquid solution or suspension (Fig. 4) [19, 25]. Finally, the residual of the solvent and unbound powder is removed under appropriate conditions, allowing for the 3D product to develop properly (post-printing step) [14].

Powder bed 3D printing method is fast and compatible for printing a wide range of pharmaceutical substances. Further, the quality of fabricated 3D products is high and contributes to a considerable reduction in the production cost. The method has great potentials for fabricating high dose formulations of drug substance, controlled and immediate release drug formulation, and multilayer tablets containing different and precise active substances. These advantages have led to wide adoption of this technique in pharmaceutical applications [41].

Selecting a suitable binder and concentration can result in the appropriate integrity of 3D drug products. Further, the particle size of the powder is another major factor which affects the quality of the final 3D products [19].

\subsubsection{Inject printing}

Another adoption of 3D printing in pharmaceutics is inject printing. This approach is particularly suitable when the formulation of starting materials is liquid [42]. Inject printing is classified into two categories: continuous inject printing (CI) and drop on demand (DOD) based on the direction of droplets (Fig. 5a,b) [31]. In the case of $\mathrm{CIJ}$, the drops are formed by a transducer or a droplet loading apparatus producing a continuous stream of droplets. Then, the droplets are directed to an electrically charged element to obtain the desired charge. Finally, the formed droplets reach onto the substrate and create the $3 \mathrm{D}$ product.

In the DOD printing system, the pharmaceutical-based ink is converted to a droplet form by applying a voltage to a piezoelectric crystal transducer to vibrate the materials or heating the formulation to the temperature higher than the boiling temperature thereby creating droplets. Then, the dots of the solution are driven from an orifice to the printer head's nozzle and solidified dropwise. The main criterion in developing a formula of API for printing in the inject print system is the performance of the carrier formulation during printing, which is strongly influenced by rheological parameters such as fluid viscosity, velocity, and surface tension [43-45]. Likewise, the release profile of the formulation can be modified given the deposition pattern of droplets onto the substrate.

The main advantage of inject printing method in the pharmaceutical application is its high accuracy in creating 3D drug products. The technology also opens up new possibility for usage of new active pharmaceutical ingredients and personalisation in drug discovery [35]. Experimental studies have shown potential applications of inject printing approach for fabricating oral dosage forms such as poorly soluble and potent drugs $[12,46]$.

The factors affecting the fabrication of 3D drug products contributing to the material and manufacturing process are listed in Table 1.

\subsection{Challenges associated with different 3D printing techniques}

Although there are many advantages associated with the production of pharmaceuticals products using 3D technology,

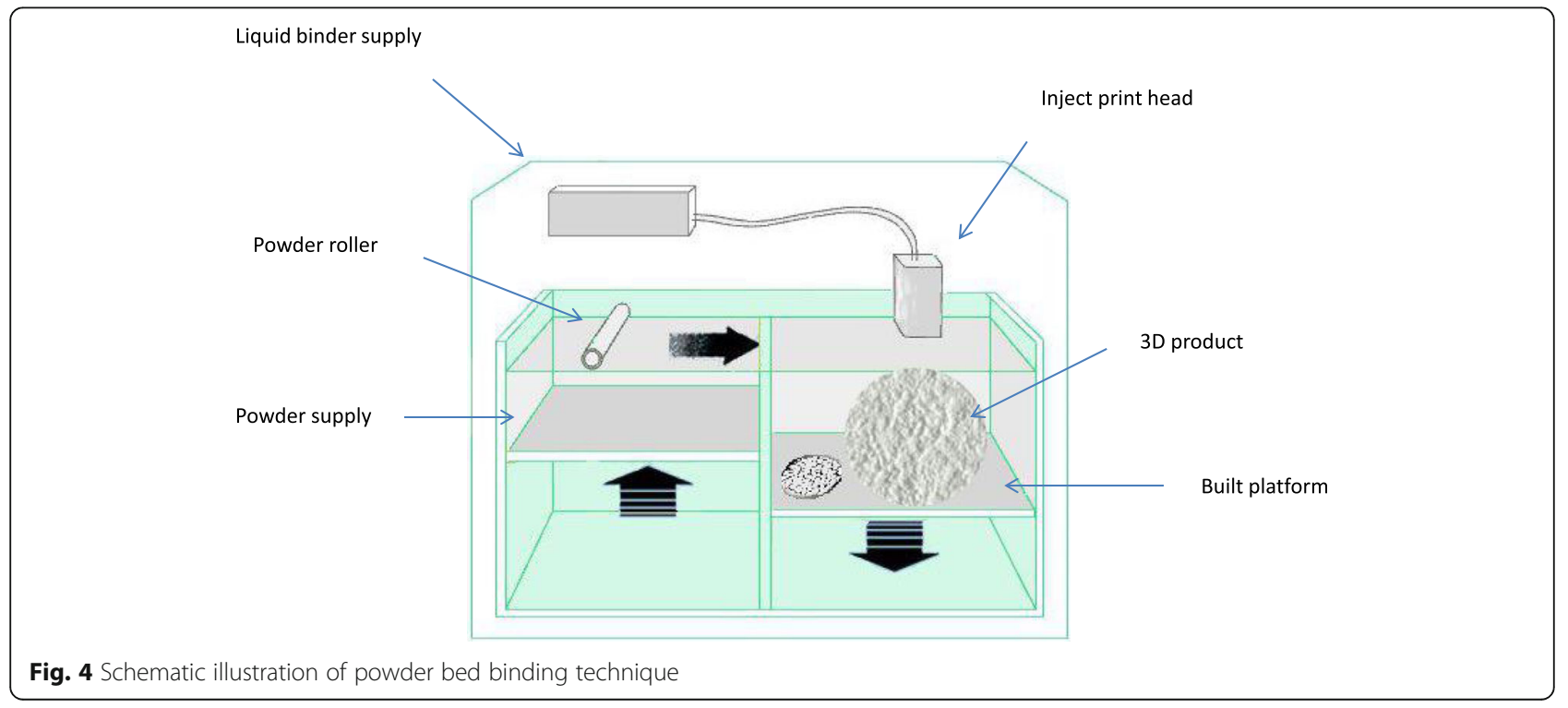



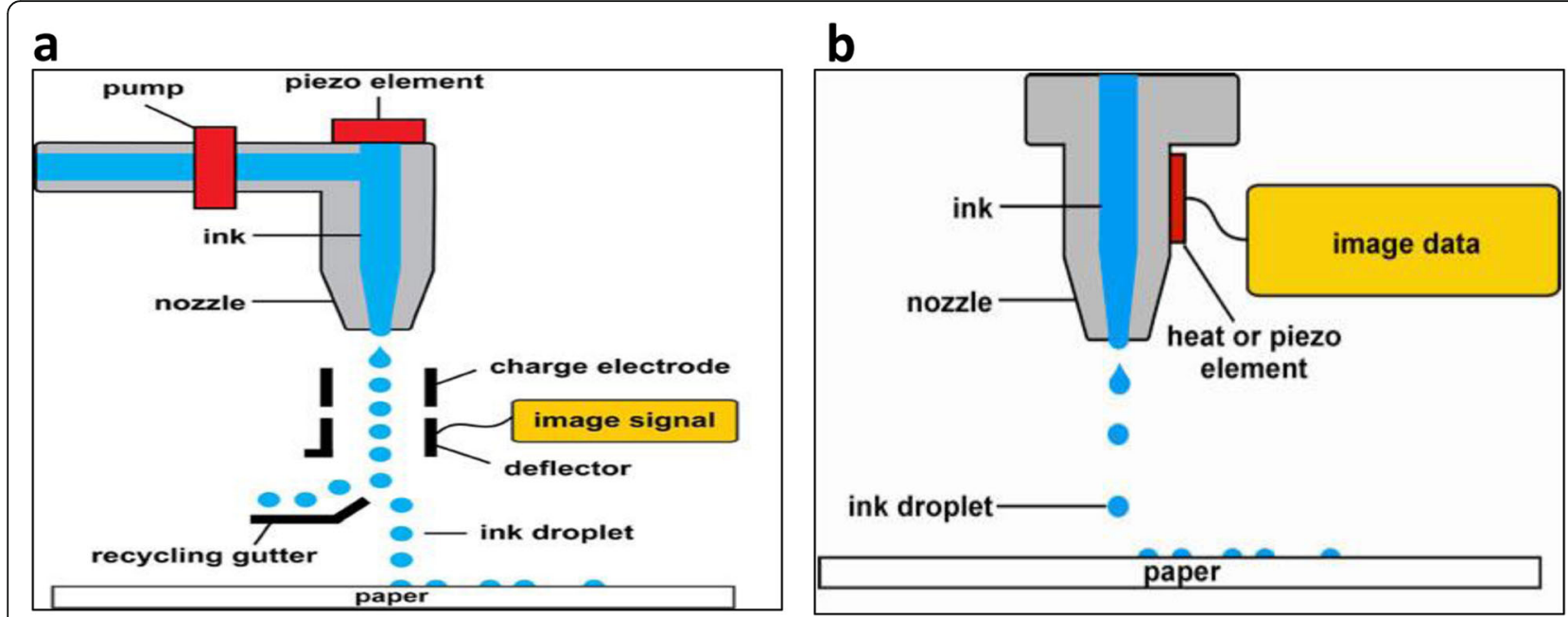

Fig. 5 Inject printing technique (a) continuous (CIJ), (b) drop on demand (DOD). Permission to reprint the figure has been obtained from Image Permanence Institute (http://www.imagepermanenceinstitute.org)

each technique has its own challenges which can restrict the application of the method. A significant drawback of extrusion-based printing method is usage of high energy input in this technique (typical temperature printing, 200-260) which has raised concern over degradation of thermosensitive materials, thus limiting it mostly to thermo-stable materials. The fabricated 3D product may collapse during 3D printing if a constructed layer cannot harden sufficiently to withstand the weight of the successive layers, which could lead to a low hardness and highly friable 3D product. Also, controlling the flow of semi-solid materials is difficult through the nozzle and the resolution of printing is limited by the nozzle size [14, 21].

In the case of fused filament technique, filaments should be prepared before loading the drug substance by a specific method and the technique is confined to thermoplastic polymers. Drug loading in the filament is usually achieved through incubation in organic solvents, and poor drug loading may limit its usage for low-dosed drugs [36].

Considering the limitation of 3D printing via the powder bed technique, 3D printed products usually require additional drying steps to remove residual solvents and improve the physical resistance. Furthermore, a remarkable wastage of powder is produced during the fabrication process. Also, there is less flexibility in terms of mistake improvement for 3D products during the fabrication process [41].

Finally, inject printing has few limitations: the droplet size is $10-50 \mu \mathrm{m}$ which may limit the printing efficacy and as a result the manipulation of the drug load. Obtaining higher doses will otherwise imply numerous printings on a particular area, which could lead to a longer drying time and potential instabilities. Also, the materials should be dissolved in a safe volatile solvent, which is another restriction for this method [12].

Table 1 Main critical factors affecting the manufacturing a 3D printing product

\begin{tabular}{|c|c|c|c|c|}
\hline Methods & Range of material & Process critical factors & Material critical factors & References \\
\hline $\begin{array}{l}\text { Extrusion based } \\
\text { printing }\end{array}$ & $\begin{array}{l}\text { Liquid, past, } \\
\text { gel, slurry }\end{array}$ & $\begin{array}{l}\text { Nozzle orifice diameter, extrusion temperature, } \\
\text { cooling rate extrusion pressure, speed of } \\
\text { traveling printing profile, feeding rate, fill } \\
\text { percentage } \\
\text { Line spacing. }\end{array}$ & $\begin{array}{l}\text { Type of polymer, molecular weight, viscosity, } \\
\text { glass transition temperature, strength, } \\
\text { toughness, type of plasticizer and its } \\
\text { concentration, polymer to drug ratio, Filament } \\
\text { diameter. } \\
\text { Kind of solvent to load drug into filament. }\end{array}$ & {$[36,37,47,48]$} \\
\hline $\begin{array}{l}\text { Powder bed } \\
\text { technique }\end{array}$ & $\begin{array}{l}\text { Powder, liquid } \\
\text { binder }\end{array}$ & $\begin{array}{l}\text { Printer head shape, number, speed, and its } \\
\text { movement pattern layer thickness } \\
\text { Powder bed spreading speed, powder bed } \\
\text { temperature } \\
\text { Speed of drying of powder bed between } \\
\text { layers } \\
\text { Temperature of heater in post printing step. }\end{array}$ & $\begin{array}{l}\text { Powder particle size, shape and density, } \\
\text { moisture content. } \\
\text { Binder concentration, viscosity, surface tension, } \\
\text { thermal capacity, electrical Conductivity, } \\
\text { droplet volume. }\end{array}$ & {$[14,19,27]$} \\
\hline Material jetting & Liquid & $\begin{array}{l}\text { Droplet flight path } \\
\text { Surface wetting } \\
\text { Jetting heating system and its temperature. }\end{array}$ & $\begin{array}{l}\text { Droplet cauterization like size concentration/ } \\
\text { viscosity/ionic strength and stability, Kind of } \\
\text { solvent. }\end{array}$ & {$[1,12,19]$} \\
\hline
\end{tabular}




\subsection{Disruptive effect of 3D printing technique in drug delivery systems}

The significant ability of 3D printing in the fabrication of solid oral dosage forms is its flexibility, which can potentially promote creativity and innovation. The new technology enables possibilities to create unique new oral drug products, which traditional methods fail to emulate $[49,50]$. 3D printing most likely corresponds to novel architectural innovation and enables designing and fabricating oral dosage forms with different geometrics, complex features such as tablets with a designed internal structure, porosity gradients, torture channels, and multi-compartment systems such as poly-pills containing multiple API in one dosage forms. These features may enable the control of drug release rate by obtaining specific and complex release patterns in response to the patient's needs, thereby enhancing the drug efficacy [51]. Concerning customized medicine, clinical pharmacists or doctors may need patient's individual information such as age, gender, body mass index, and metabolism in order to develop the optimum medical dose. In this way, the patient can receive accurate personalized treatment regimen matching their particular medical profile [46]. Current research into 3D printing technology as a tool within pharmaceutical research and production has focused on small scale manufacturing to enable individualisation and utilization, as well as to increase compliance.

The following section thoroughly discusses the impact of $3 \mathrm{D}$ printing technique in various manufacturing processes and assesses their result via in vitro or in vivo evaluation from 3D oral drug products with some examples of recent literature. Other examples of 3D oral dosage forms manufactured with 3D printing technology are tabulated in Table 2.

\subsubsection{D printing of tablets with various geometries to achieve a tailored function}

Goyanes et al. explored the feasibility of using a fused filament method to fabricate tablets of different shapes and sizes. Acetaminophen-loaded filaments of PVA were prepared by introducing an aqueous solution of paracetamol $(2 \% \mathrm{w} / \mathrm{w})$ in small pieces of PVA with Varicut as a plasticizer. Then, the formula was printed with different shapes as cube, pyramid, cylinder, sphere, and torus using a single-screw filament extruder. The printed geometries were considered to be reproducible, precise, and printable at a size suited to mass production.

They found that manipulation of the printed geometry of acetaminophen tablets resulted in varying drug release rates, allowing for a high degree of personalisation. The pyramid-shaped tablet of acetaminophen which had the largest surface area to volume ratio revealed the fastest release rate, while the cylinder-shaped tablet with the smallest ratio indicated the slowest release rate of the drug.

Further, their study proved that different-shaped tablets had a great impact on transit time in vivo which may also be beneficial for developing targeted drug delivery systems to a specific gastro-intestine site [37].

Table 2 Proprietary 3D printing drug products

\begin{tabular}{|c|c|c|c|}
\hline Drug product & Fabrication technique & Dosage Form Characteristics & References \\
\hline Acetaminophen controlled release tablet & Hot melt extrusion & $\begin{array}{l}\text { Specific 3D structure with different inner core } \\
\text { densities and outer shell thickness. }\end{array}$ & [52] \\
\hline Warfarin fast disintegrating tablet & Powder based method & $\begin{array}{l}\text { Highly porous structure which disintegrates } \\
\text { very fast in oral cavity. }\end{array}$ & [53] \\
\hline Aripiprazoleoro dispersible films & Fused filament method & $\begin{array}{l}\text { Printed film with a porous structure and } \\
\text { amorphization of the drug substance. }\end{array}$ & [54] \\
\hline $\begin{array}{l}\text { Colon delivery tablet of aminosalicylate } \\
\text { (4- ASA and 5-ASA) }\end{array}$ & Hot melt extrusion & $\begin{array}{l}\text { Monolithic controlled release tablet as } \\
\text { patient-tailored medicine. }\end{array}$ & [55] \\
\hline $\begin{array}{l}\text { Theophylline immediate and extended } \\
\text { release tablet }\end{array}$ & Hot melt extrusion & $\begin{array}{l}\text { A combination of different release } \\
\text { mechanisms into a single system with digital } \\
\text { control of excipients. }\end{array}$ & [56] \\
\hline Fluorescein 3D printing tablet & Fused filament method & $\begin{array}{l}\text { Monolithic tablet for personalized } \\
\text { dosemedicine and specific release profile. }\end{array}$ & [36] \\
\hline Prednisolone extended release 3D tablet & Fused filament method & $\begin{array}{l}\text { Amorphization of prednisolone in formulation } \\
\text { /personalized dose medicine. }\end{array}$ & [57] \\
\hline Ritonavir 3D tablet & Hot melt extrusion & $\begin{array}{l}\text { Solid dispersion of drug in hydrophilic } \\
\text { polymer to improve the drug solubility and } \\
\text { bioavailability. }\end{array}$ & [24] \\
\hline $\begin{array}{l}\text { 3D tablet containing nanocapsule of } \\
\text { deflazacort }\end{array}$ & Fused filament method & $\begin{array}{l}\text { Combination of two technology; 3D printing } \\
\text { and nanotechnology to create innovative } \\
\text { formulation. }\end{array}$ & [58] \\
\hline
\end{tabular}




\subsubsection{D printing of tablets with honeycomb architecture as different levels of complexity to control and tuneable drug release rate}

Kyobulaa et al. developed a modified release tablet of fenofibrate with 3D inject printing technique using molten beeswax (FDA approved wax) as a hydrophobic drug carrier. Application of beeswax in the formulation of tablets is generally safe and provides a means for controlling the release of active ingredient from the dosage form. The molten combination of fenofibrate and beeswax was prepared using a magnetic stirrer hotplate at $90{ }^{\circ} \mathrm{C}$ and then printed in a honeycomb architecture without using any solvent. The main characteristic of this type of $3 \mathrm{D}$ tablet is its potential to provide customized drug loading and facilitating the drug distribution within the tablet which may ultimately enhance the drug release rate. This result is based on the fact that by manipulating key geometric parameters such as cell size, wall surface area, and shell thickness, the drug dissolution rate will also be affected.

The results of this study suggested that the increase in honeycomb diameter and surface led to an increase in the amount of released drug in the case of honeycomb with a middle-sized channel. Tablets with the smallest and widest dimension honeycombs showed a reduction in the dissolution rate of the drug due to insufficient penetration of dissolution medium and lower surface area respectively, when compared with a middle-sized channel. Further, the benefits of this system include its flexibility for manipulation of different geometries for personalized medicines or a pattern for different drugs, without the need to change the basic formulation composition, processing parameters, and the manufacturing equipment. In addition, this system has a potential to mask the bad taste of the drug. The study also found inkjet printing system to be a more precise and effective method for fabricating different doses of poorly soluble drugs [59].

\subsubsection{D tablets for systemic effect with a fast onset of action}

Spirtam $^{\odot}$ (levapiracetam) is the first 3D commercial tablet produced by Aprecia Pharmaceuticals (the first Pharmaceutical which started to integrate $3 \mathrm{D}$ printing in one of its products) and approved by FDA in August 2015. It is a complex, pyramid-shaped and immediaterelease $3 \mathrm{D}$ tablet manufactured by powder bed binding technique without applying compression. The 3D tablet has a highly porous scaffold even at high doses $(1000 \mathrm{mg}$ of API) enabling fast disintegration in the patient's mouth with a little amount of water. The new 3D tablet offers the advantage of reducing the lag time for the onset of action since a large proportion of the drug is available for absorption via the oral mucosa into the general circulation. Also, this kind of formulation can open up a new way in designing dosage forms for patients who struggle to swallow a tablet $[14,46]$.

\subsubsection{D hollow structure tablets to improve the solubility and bioavailability and extend the release pattern}

A novel enabling strategy to increase the solubility and bioavailability of the poorly soluble drug "domperidone" with 3D printing technique was introduced by Chai et al. The developed 3D tablet represented a new concept as a gastro-retentive system with an extended release pattern using the fused disposition modeling. Domperidone was loaded onto a hydrophilic carrier of hydroxypropyl cellulose (HPC) filament as solid dispersion and printed into a hollow structure tablet. The shape of the hallow structure was controlled with two main factors including the numbers of shell and infill percentage which may affect the outline and inner part of the 3D object, respectively. Increasing the number of shells will add the weight and strength of the tablet. On the other hand, reducing the infill percentage during the printing leads to increased porosity of the tablet, thereby improving the dissolution rate. The result of their study showed that the proposed formulation of the 3D tablet with two shells, zero percent infill and density of $0.77 \mathrm{~g} /$ $\mathrm{cm}^{3}$, had a rigid hallow internal structure which could dissociate slowly and provide sustained release rate with a floating ability up to $10 \mathrm{~h}$ both in vitro and in vivo. The enhanced concentration of the drug with less fluctuations in the rabbit plasma and consequently improved oral bioavailability of domperidone after oral administration of single-dose of the tablet to the rabbit revealed that the $3 \mathrm{D}$ gastro floating tablet had a potential to reduce the frequency of drug administration and to improve the drug's efficacy [47].

\subsubsection{Nanosuspension strategy for accurate dosing of poorly water-soluble drugs in personalized medicine}

Jana et al. worked on an approach to develop a nanosuspension system for folic acid as a model of poorly watersoluble drug. They employed inkjet printing system to produce personalized medicines. A $10 \%$ of folic acid suspension was prepared by mortar and pestle of folic acid in the presence of $3 \%(\mathrm{w} / \mathrm{w})$ Tween 20 . The nanosuspension was then created using a special homogenizer under controlled pressure. The particle size distribution of folic acid in the nanosuspension formulation was determined below $5 \mu \mathrm{m}$ by a laser diffractometry system. A piezoelectric inkjet printer system with a nozzle apparatus of $100 \mu \mathrm{m}$ was employed for printing. The result of their study indicated that the saturated solubility and dissolution rate of folic acid nanosuspension significantly increased by up to $57 \%$ and $12.5 \%$, respectively, compared to folic acid microsuspension. The authors concluded 
that faster and more accurate dissolution profiling can be adjusted via formulating the nanosuspension of folic acid using an inject printing method. Also, the printed dosage forms were found to be chemically and physically stable under ambient conditions [60].

\subsubsection{D printed buccal film for oral delivery of protein and peptide}

Biomedical molecules such as protein and peptides represent great pharmaceutical challenges which cannot be processed and administered via oral delivery routes. The major issue related to insufficient efficacy and bioavailability is attributed to their retention of structure and instability in gastrointestinal fluids. In a study conducted by Miguel et al., they developed a printed buccal oral film of two kinds of proteins including lysozyme and ribonuclease-A which were extracted from egg chicken and bovine pancreas. They employed thermal inkjet printing system adapted for printing biological materials. The ink formula for printing contained a protein solution in water and glycerine (a viscosity modifier) with a ratio of 70:30. Sodium deoxycholate was also added into the ink formulation as a permeation enhancer. The printed films were evaluated by different analysis methods to test the protein quantity, structure, efficacy, and enzyme activity. The results of their study indicated that the 3D buccal film was successfully printed by a conventional printer. No changes occurred in the protein structure nor in their enzyme activity after the printing process. The study concluded that the thermal ink jet printing can be used as an efficient and practical approach for preparing biological buccal oral films without compromising the protein activity [61].

\subsubsection{Pediatric-printed tablets}

Scoutaris et al. managed to fabricate a 3D tablet of indomethacin in the form of Starmix ${ }^{\circ}$ designs for pediatrics. Indomethacin was incorporated onto hypromellose acetate succinate (HMPCAS) thermoplastic polymer and transformed into a 3D tablet via the extrusion method. The study involved coupling both extrusion systems, HME and the FDM, to fabricate chewable tablets of Starmix form. The printing method with HME can mask the bitter taste of the drug substance. Through choosing a suitable taste-masking polymer via solid dispersion with API, and as FDM can fabricate any shape of 3D product, a combination of two methods led to fabrication of tablets with a favorite shape and taste, being more attractive and desired by children.

Their research team proposed that the printing technology enables fabricating 3D tablets of indomethacin in the form of a heart, ring, bottle, ring, bear, and lionshape combined with effective sweetening. This may be a promising substitute for indomethacin conventional tablet, thereby improving compliance for pediatric patients. The results of the dissolution study showed immediate release of indomethacin within $60 \mathrm{~min}$, regardless of the printed shape of tablets [62].

\subsection{D printing role in local and home fabrication}

The final stage of adoption of $3 \mathrm{D}$ printing in the pharmaceutical application is local or home fabrication 3D printers in a mini-dispenser unit which first emerged in 2010. The fabrication of 3D medical products is performed directly by patients themselves with a personal $3 \mathrm{D}$ printing device at home or a local printer in different situations such as pharmacy, clinic, or an emergency condition only with a single fabrication run. The starting material should be provided in mass-production for the final manufacturing step by the customer. In this case, the medical care providers and patients must be educated well enough on how to use the printer and how to evaluate the quality defects which may appear in the printed product. This kind of adoption will enable bypassing the distribution stage which would be more economical to manufacture a smaller batch of a medicine rapidly. Tissue engineering scaffolds and woundhealing gels are two practical examples for application of local printing technique which are mostly performed via the extrusion technique by a doctor [13, 26, 63].

According to recent literature review, the number of local or home 3D printing devices is limited and restricted mainly to engineering studies. Further, apart from the importance of the value and potential of $3 \mathrm{D}$ printing in pharmaceutical development, there is much more debate about home fabrication which can be performed by patients themselves. The reasons about the unsuitability of this technique at home or other local places include low quality product, high cost, and limited materials which can be used. One of the drawbacks which can raise concerns over the product responsibility would be related to granting permission of license of production for the desired drug product from the pharmaceutical company to pharmacies and patients who intend to produce the product locally. This may raise the problem of adverse incidence or claims of product defects. In addition to the on-demand 3D printing production outside the pharmaceutical companies by healthcare centers or pharmacies, another concern is hackers making alternative drug formulations which can cause serious implications for the patient $[63,64]$.

\section{Conclusion}

3D printing technology represents a great potential in drug development, formulation, and administration due to its great flexibility and efficacy in innovation and creation of novel medical products. In addition, the suitability of the technology as a tool for drug individualisation 
is massive given its ability to manipulate high degrees of drug deposition pattern to assess different release profiles. The new technique allows for reformulating and remanufacturing a medical formulation to distinguish it from generics competition in the market, which can provide supplementary patient benefits and ultimately leads to diminished cost of product.

The mini review focused on a limited number of experimental studies to explore the practicalities of 3D printing technology in manufacturing oral pharmaceutical dosage forms. The selected studies showed success in the use of the current development for manufacturing oral drug products. In most cases, poorly water-soluble drugs were included, which are the main challenges in the pharmaceutical industry. The studies indicated that using a suitable 3D printing method and well-formulated pharmaceutical ink for printing, higher solubility and bioavailability of poorly soluble drugs can be achieved.

Note that standardization of equipment is required in addition to ensuring the safety of ancillary equipment. Similarly, development of a suitable ink formulation for printing should fulfill both the physical and chemical criteria for a successful 3D drug production.

Overall, printing technique has gained much attraction in research and development in the pharmaceutical field, but the full success in this area will be achieved after obtaining elaborated novel fabricated 3D dosage forms on an industrial scale.

\section{Abbreviations}

3DP: Three-dimensional printing; API: Active drug pharmaceutical ingredients; CAD: Computer-aided design; CIJ: Continuous inject printing; DOD: Drop on demand; FDA: Food and Drug Administration; FF: Fussed filament; GMP: Good Manufacturing Practices; HME: Melt extrusion; HPC: Hydroxypropyl cellulose; MIT: Massachuset Institute Technology; PLA: Polylactic acid; PVA: Polyvinyl alcohol; STL: Stereo lithography

\section{Acknowledgements}

The author wish to thank Dr. Shabnam Sani (Western New England University) for her kind comments that greatly improved the manuscript.

\section{Author's contributions}

The single author did all the work. The author read and approved the final manuscript.

\section{Funding}

This project was financially supported by the FakherPharma Pharmaceutical Company under grand submission of FIRC 1194 for providing access to literature.

\section{Availability of data and materials}

Not applicable.

\section{Ethics approval and consent to participate}

Not applicable.

\section{Consent for publication}

Not applicable.

\section{Competing interests}

The author declares that they have no competing interests.
Received: 5 November 2019 Accepted: 7 February 2020

Published online: 14 May 2020

\section{References}

1. Hsiao WK, Lorber B, Reitsamer H (2018) 3D printing of oral drugs: a new reality or hype? Expert Opin Drug Deliv 15:1-4. https://doi.org/10.1080/ 17425247.2017 .1371698

2. Scoutaris N, Ross S, Douroumis D (2016) Current trends on medical and pharmaceutical applications of inkjet printing technology. Pharm Res 33(8): 1799-1816. https://doi.org/10.1007/s11095-016-1931-3

3. Zhang J, Vo AQ, Feng X (2018) Pharmaceutical additive manufacturing: a novel tool for complex and personalized drug delivery systems. AAPS PharmSciTech 19:3388-3402. https://doi.org/10.1208/s12249-018-1097-x

4. Awad A, Trenfield SJ, Gaisford S (2018) 3D printed medicines: a new branch of digital healthcare. Int J Pharm 548(1):586-596. https://doi.org/10.1016/j. ijpharm.2018.07.024

5. Konta AA, Garcia-Pina M, Serrano DR (2017) Personalised 3D printed medicines: which techniques and polymers are more successful? Bioengineering (Basel, Switzerland) 4 (4). https://doi.org/10.3390/ bioengineering4040079

6. Shafiee A, Atala A (2016) Printing technologies for medical applications. Trends Mol Med 22(3):254-265. https://doi.org/10.1016/j. molmed.2016.01.003

7. El Aita I, Ponsar H, Quodbach J (2018) A critical review on 3D-printed dosage forms. Curr Pharm Des. https://doi.org/10.2174/ 1381612825666181206124206

8. Norman J, Madurawe RD, Moore CMV (2017) A new chapter in pharmaceutical manufacturing: 3D-printed drug products. Adv. Drug Deliv. Rev 108:39-50. https://doi.org/10.1016/j.addr.2016.03.001

9. Liaw CY, Guvendiren M (2017) Current and emerging applications of 3D printing in medicine. Biofabrication 9(2):024102. https://doi.org/10.1088/ 1758-5090/aa7279

10. Peng W, Datta P, Ayan B (2017) 3D bioprinting for drug discovery and development in pharmaceutics. Acta Biomater 57:26-46. https://doi.org/10. 1016/j.actbio.2017.05.025

11. Prasad LK, Smyth H (2016) 3D Printing technologies for drug delivery: a review. Drug development and industrial pharmacy 42(7):1019-1031. https://doi.org/10.3109/03639045.2015.1120743

12. Daly R, Harrington TS, Martin GD (2015) Inkjet printing for pharmaceutics - a review of research and manufacturing. Int J Pharm 494(2):554-567. https:// doi.org/10.1016/j.ijpharm.2015.03.017

13. Ursan ID, Chiu L (2003) Pierce A (2013) Three-dimensional drug printing: a structured review. J Am Pharm Assoc 53(2):136-144. https://doi.org/10.1331/ JAPhA.2013.12217

14. Jamroz W, Szafraniec J, Kurek M (2018) 3D printing in pharmaceutical and medical applications - recent achievements and challenges. Pharm Res 35(9):176. https://doi.org/10.1007/s11095-018-2454-x

15. Palo M, Hollander J, Suominen J (2017) 3D printed drug delivery devices: perspectives and technical challenges. Expert Rev Med Devices 14(9):685696. https://doi.org/10.1080/17434440.2017.1363647

16. Park K (2015) 3D printing of 5-drug polypill. J Control Release 217:352 https://doi.org/10.1016/j.jconrel.2015.10.014

17. Sun Y, Soh S (2015) Printing tablets with fully customizable release profiles for personalized medicine. Advanced materials (Deerfield Beach, Fla.) 27 (47):7847-7853. https://doi.org/10.1002/adma.201504122

18. Trenfield SJ, Awad A, Goyanes A (2018) 3D Printing pharmaceuticals: drug development to frontline care. Trends Pharmacol Sci 39:440-451. https:// doi.org/10.1016/j.tips.2018.02.006

19. Goole J, Amighi K (2016) 3D printing in pharmaceutics: a new tool for designing customized drug delivery systems. Int J Pharm 499(1):376-394. https://doi.org/10.1016/j.jpharm.2015.12.071

20. Osouli-Bostanabad K, Adibkia K (2018) Made-on-demand, complex and personalized 3D-printed drug products. Biolmpacts : BI 8 (2):77-79. doi:10. 15171/bi.2018.09

21. Khatri P, Shah MK, Vora N (2018) Formulation strategies for solid oral dosage form using 3D printing technology: a mini-review. J DRUG DELIV SCI TEC 46:148-155. https://doi.org/10.1016/j.jddst.2018.05.009

22. Lim SH, Kathuria H, Tan JJY (2018) 3D printed drug delivery and testing systems - a passing fad or the future? Adv. Drug Deliv. Rev 132:139-168. https://doi.org/10.1016/j.addr.2018.05.006 
23. Sun Y, Soh S (2015) Printing tablets with fully customizable release profiles for personalized medicine. Advanced materials (Deerfield Beach, Fla.) 27. 7847-7853. https://doi.org/10.1002/adma.201504122

24. Tan DK, Maniruzzaman M, Nokhodchi A (2018) Advanced pharmaceutical applications of hot-melt extrusion coupled with fused deposition modelling (FDM) 3D printing for personalised drug delivery. Pharmaceutics 10(4). https://doi.org/10.3390/pharmaceutics10040203

25. Khaled SA, Burley JC, Alexander MR (2014) Desktop 3D printing of controlled release pharmaceutical bilayer tablets. Int J Pharm 461(1-2):105111. https://doi.org/10.1016/j.ijpharm.2013.11.021

26. Zema L, Melocchi A, Maroni A (2017) Three-dimensional printing of medicinal products and the challenge of personalized therapy. J Pharm Sci 106:1697-1705. https://doi.org/10.1016/j.xphs.2017.03.021

27. Rahman Z, F. Barakh Ali S, Ozkan T (2018) Additive manufacturing with 3D printing: progress from bench to bedside, vol 20. doi:10.1208/s12248-0180225-6

28. Ameeduzzafar RM, Abbas Bukhari SN (2019) 3D printing technology in design of pharmaceutical products. Curr Pharm Des. https://doi.org/10.2174/ 1381612825666190116104620

29. Rayna T, Striukova L (2016) From rapid prototyping to home fabrication: how 3D printing is changing business model innovation. Technol. Forecast. Soc. Change 102:214-224. https://doi.org/10.1016/j.techfore.2015.07.023

30. Long J, Gholizadeh H, Lu J (2017) Application of fused deposition modelling (FDM) method of 3D printing in drug delivery. Curr Pharm Des 23(3):433439. https://doi.org/10.2174/1381612822666161026162707

31. Preis M, Breitkreutz J, Sandler N (2015) Perspective: concepts of printing technologies for oral film formulations. International Journal of Pharmaceutics 494(2):578-584. https://doi.org/10.1016/j.jpharm.2015.02.032

32. Nematollahi B, Xia M, Sanjayan J (2017) Current progress of 3D concrete printing technologies. doi:10.22260/ISARC2017/0035

33. Melocchi A, Parietti F, Maroni A (2016) Hot-melt extruded filaments based on pharmaceutical grade polymers for 3D printing by fused deposition modeling. Int. J. Pharm 509(1):255-263. https://doi.org/10.1016/j.ijpharm. 2016.05.036

34. Solanki NG, Tahsin M, Shah AV (2018) Formulation of 3D printed tablet for rapid drug release by fused deposition modeling: screening polymers for drug release, drug-polymer miscibility and printability. J. Pharm. Sci 107(1): 390-401. https://doi.org/10.1016/j.xphs.2017.10.021

35. Alomari M, Mohamed FH, Basit AW (2015) Personalised dosing: printing a dose of one's own medicine. Int J Pharm 494:568-577. https://doi.org/10. 1016/j.ijpharm.2014.12.006

36. Goyanes A, Buanz AB, Basit AW (2014) Fused-filament 3D printing (3DP) for fabrication of tablets. Int J Pharm 476(1-2):88-92. https://doi.org/10.1016/j. ijpharm.2014.09.044

37. Goyanes A, Robles Martinez P, Buanz A (2015) Effect of geometry on drug release from 3D printed tablets. Int. J. Pharm 494:657-663. https://doi.org/ 10.1016/j.jpharm.2015.04.069

38. Agrawal A, Dudhedia M, Deng W (2016) Development of tablet formulation of amorphous solid dispersions prepared by hot melt extrusion using quality by design approach. AAPS PharmSciTech 17(1):214-232. https://doi. org/10.1208/s12249-015-0472-0

39. Lee BK, Yun YH, Choi JS (2012) Fabrication of drug-loaded polymer microparticles with arbitrary geometries using a piezoelectric inkjet printing system. Int J Pharm 427(2):305-310. https://doi.org/10.1016/j.jpharm.2012.02.011

40. Wickstrom H, Palo M, Rijckaert K (2015) Improvement of dissolution rate of indomethacin by inkjet printing. Eur J Pharm Sci 75:91-100. https://doi.org/ 10.1016/j.ejps.2015.03.009

41. Infanger S, Haemmerli A, lliev S (2019) Powder bed 3D-printing of highly loaded drug delivery devices with hydroxypropyl cellulose as solid binder. Int. J. Pharm 555:198-206. https://doi.org/10.1016/j.jpharm.2018.11.048

42. Scoutaris N, Alexander MR, Gellert PR (2011) Inkjet printing as a novel medicine formulation technique. J. Control. Release 156(2):179-185. https:// doi.org/10.1016/j.jconrel.2011.07.033

43. Boehm RD, Miller PR, Daniels J (2014) Inkjet printing for pharmaceutical applications. Materials Today 17(5):247-252. https://doi.org/10.1016/j.mattod. 2014.04.027

44. Hirshfield L, Giridhar A, Taylor LS (2014) Dropwise additive manufacturing of pharmaceutical products for solvent-based dosage forms. J Pharm Sci 103(2):496-506. https://doi.org/10.1002/jps.23803
45. Thabet Y, Lunter D, Breitkreutz J (2018) Continuous inkjet printing of enalapril maleate onto orodispersible film formulations. Int J Pharm 546(1): 180-187. https://doi.org/10.1016/j.jpharm.2018.04.064

46. Alhnan MA, Okwuosa TC, Sadia M (2016) Emergence of 3D printed dosage forms: opportunities and challenges. Pharm Res 33:1817-1832. https://doi. org/10.1007/s11095-016-1933-1

47. Chai X, Chai H, Wang X (2017) Fused deposition modeling (FDM) 3D printed tablets for intragastric floating delivery of domperidone. Scientific Reports 7:2829. https://doi.org/10.1038/s41598-017-03097-x

48. Aho J, Boetker JP, Baldursdottir S (2015) Rheology as a tool for evaluation of melt processability of innovative dosage forms. Int J Pharm 494:623-642. https://doi.org/10.1016/j.ijpharm.2015.02.009

49. Sadia M, Arafat B, Ahmed W (2018) Channelled tablets: an innovative approach to accelerating drug release from 3D printed tablets. J Control Release 269:355-363. https://doi.org/10.1016/j.jconrel.2017.11.022

50. Wen H, He B, Wang H (2019) Structure-based gastro-retentive and controlled-release drug delivery with novel 3D printing. AAPS PharmSciTech 20:68. https://doi.org/10.1208/s12249-018-1237-3

51. Preis $\mathrm{M}, \mathrm{Oblom} \mathrm{H}$ (2017) 3D-printed drugs for children-are we ready yet? AAPS PharmSciTech 18(2):303-308. https://doi.org/10.1208/s12249-016-0704-y

52. Zhang J, Yang W, Vo AQ (2017) Hydroxypropyl methylcellulose-based controlled release dosage by melt extrusion and 3D printing: structure and drug release correlation. Carbohydr Polym 177:49-57. https://doi.org/10. 1016/j.carbpol.2017.08.058

53. Tian P, Yang F, Xu Y (2018) Oral disintegrating patient-tailored tablets of warfarin sodium produced by 3D printing. Drug Dev Ind Pharm 44:19181923. https://doi.org/10.1080/03639045.2018.1503291

54. Thabet $Y$, Sibanc R, Breitkreutz J (2018) Printing pharmaceuticals by inkjet technology: proof of concept for stand-alone and continuous in-line printing on orodispersible films. J. Manuf. Process." 35:205-215. doi:https:// doi.org/10.1016/j.jmapro.2018.07.018

55. Goyanes A, Buanz AB, Hatton GB (2015) 3D printing of modified-release aminosalicylate (4-ASA and 5-ASA) tablets. Eur J Pharm Biopharm 89:157162. https://doi.org/10.1016/j.ejpb.2014.12.003

56. Pietrzak K, Isreb A, Alhnan MA (2015) A flexible-dose dispenser for immediate and extended release 3D printed tablets. Eur J Pharm Biopharm 96:380-387. https://doi.org/10.1016/j.ejpb.2015.07.027

57. Skowyra J, Pietrzak K, Alhnan MA (2015) Fabrication of extended-release patient-tailored prednisolone tablets via fused deposition modelling (FDM) 3D printing. Eur J Pharm Sci 68:11-17. https://doi.org/10.1016/j. ejps.2014.11.009

58. Beck RCR, Chaves PS, Goyanes A (2017) 3D printed tablets loaded with polymeric nanocapsules: an innovative approach to produce customized drug delivery systems. Int J Pharm 528:268-279. https://doi.org/10.1016/j. ijpharm.2017.05.074

59. Kyobula M, Adedeji A, Alexander MR (2017) 3D inkjet printing of tablets exploiting bespoke complex geometries for controlled and tuneable drug release. J Control Release 261:207-215. https://doi.org/10.1016/j.jconrel.2017. 06.025

60. Pardeike J, Strohmeier DM, Schrödl N (2011) Nanosuspensions as advanced printing ink for accurate dosing of poorly soluble drugs in personalized medicines. International Journal of Pharmaceutics 420(1):93-100. https://doi. org/10.1016/j.jpharm.2011.08.033

61. Montenegro-Nicolini M, Miranda V, Morales J (2016) Inkjet printing of proteins: an experimental approach. The AAPS Journal 19. https://doi.org/10. 1208/s12248-016-9997-8

62. Scoutaris N, Ross SA, Douroumis D (2018) 3D printed "Starmix" drug loaded dosage forms for paediatric applications. Pharm Res 35(2):34. https://doi.org/ 10.1007/s11095-017-2284-2

63. Sandler N, Preis M (2016) Printed drug-delivery systems for improved patient treatment. Trends in pharmacological sciences 37(12):1070-1080. https://doi.org/10.1016/j.tips.2016.10.002

64. Pravin S, Sudhir A (2018) Integration of 3D printing with dosage forms: a new perspective for modern healthcare. Biomedicine \& Pharmacotherapy 107:146-154. https://doi.org/10.1016/j.biopha.2018.07.167

\section{Publisher's Note}

Springer Nature remains neutral with regard to jurisdictional claims in published maps and institutional affiliations. 